\title{
DUPLICATION OF EXTRAHEPATIC BILE DUCT IN ASSOCIATION WITH CHOLELITHIASIS.
}

Rohit Kumar Jha,Nishith Ekka,Shital Malua, Pankaj Bodra, Krishna Murari, Ranveer Singh Rana, Shayam Charan Baskey

\footnotetext{
1. Senior Resident. Department of General Surgery, Rajendra Institute of Medical Sciences.

2. Senior Resident. Department of General Surgery, Rajendra Institute of Medical Sciences.

3. Associate Professor. Department of General Surgery, Rajendra Institute of Medical Sciences.

4. Assistant Professor. Department of General Surgery, Rajendra Institute of Medical Sciences.

5. Assistant Professor. Department of General Surgery, Rajendra Institute of Medical Sciences.

6. Junior Resident. Department of General Surgery, Rajendra Institute of Medical Sciences.

7. Junior Resident. Department of General Surgery, Rajendra Institute of Medical Sciences.
}

\section{CORRESPONDING AUTHOR:}

Dr. Rohit Kumar Jha

Flat no.-a/303, Urmila enclave,

Peace Road,Lalpur,

Ranchi,Jharkhand-834001.

E-mail: withrohitjha@gmail.com

ABSTRACT: A case of duplication of extrahepatic bile duct in association with cholelithiasis is presented. Precise preoperative recognition of this anomaly is extremely rare. Preoperative adequate appreciation of these anomalies of the biliary tree prevents surgeons from impairing the anomalous bile ducts, or from going astray, being faced with these anomalies at operation accidentally.

KEY WORDS: duplication of extrahepatic bile duct in association with cholelithiasis, anomalies of the biliary tree, magnetic resonance cholangiopancreatography.

INTRODUCTION: Congenital anomalies of bile ducts are relatively common with reported prevalence of $15 \%$ based on surgical studies ${ }^{1}$. Congenital extrahepatic duplication of biliary tract, however, is extremely rare with discussions primarily limited to sporadic case reports. Duplication of common bile duct, for instance has been reported in only 24 individuals, according to review of clinical literature over 500 year period upto $1986^{2}$.

Recognition of this is clinically important as it can lead to complication such as cholelithiasis ,choledocholithiasis, cholangitis, pancreatitis and upper gastrointestinal malignancies ${ }^{3}$. In addition, this anomaly is often accompanied with anomalous union of panceatobiliaryductal system(AUPBD) and the presence of choledochal cyst ${ }^{3}$.

We present here a case of an elderly female patient who had duplication of extrahepatic bile duct along with colelithiasis. The anomaly was diagnosed intraoperatively which was postoperatively confirmed by magnetic resonance cholangiopancreatography(MRCP) ${ }^{5,6}$.

Even in most of the earlier reported cases, these anomalies were found in dissecting room or at operation and correct preoperative diagnosis of this anomaly is extremely rare ${ }^{5}$.

CASE REPORT: A 59 year old women presented with 2 day history of right upper quadrant abdominal pain. She had vague hypochondrlgia from about 2 months before admission which was pronounced after taking fatty foods. The patient denied any fever, chills, jaundice or generalised pruritus. Physical examination revealed a soft non distended abdomen with deep tenderness in right hypochondrium. There was no organomegaly or palpable lump. On 
transabdominal ultrasound, a small contracted gall bladder with multiple stones was revealed. All haematological and biochemical tests were within normal range except for a mildly elevated serum aminotransferase(45 IU/L) level.

At operation, the upper abdominal viscera appeared normal. Gall bladder was found to be contracted without any surrounding addhesions. Two large calculi were palpated, completely filling the gall bladder. The cystic duct was very short and ended abruptly in CBD. Just posteromedial to the CBD, there was another tubular structure, closely adherent to CBD which was arising from the inferior surface of liver and extending $5 \mathrm{~cm}$. distal to opening of cystic duct in CBD and finally merging with CBD to form a common channel. When dissection was made along posteromedial surface of CBD both ducts separated completely in proximal region suggesting proximal duplication of extrahepatic bile duct. Cholecystectomy was done and operation was completed. Careful retrospective review of magnetic resonance cholangiopancreatography(MRCP) confirmed the operative finding of duplication of exrahepatic bile duct with no evidence of AUPBD. Both ducts after forming a common channel was joined by pancreatic duct finally opening in second part of duodenum.

\section{DISCUSSION:}

- Duplication of extrahepatic bile duct is an extremely rare condition ${ }^{3}$.

- Mechanism of anomaly5-

- Boyden and his colleagues first reported that the duplication of the biliary system known to be normal anatomical feature of reptiles, birds and fish, is present in early human embryogenesis and thereby represents primitive structures that regress with normal development. An early disruption of development,therefore,is believed to result in in persistence of an accessory extrahepatic duct.

- Classification- Is a challenge-> Owing to unique nature of this anomaly and the wide variation of the reported cases of extrahepatic biliary duplication,precise anatomical definition and classification posed a challenge.

- Definition-> "common bile duct" in DCBD(duplication of common bile duct) literature is defined as the duct that directly drains into gastro intestinal tract irrespective of its proximal anatomy.

- Classification as per Saito et $\mathrm{al}^{9}$

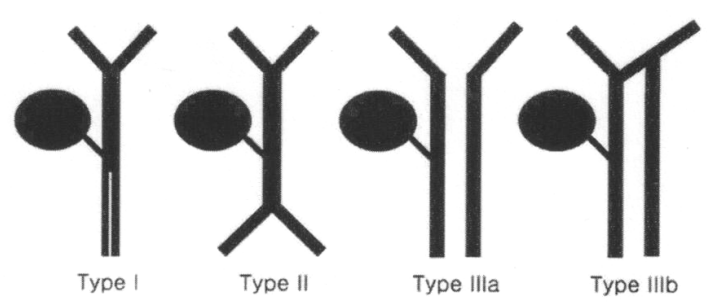

- $\mathrm{M}$

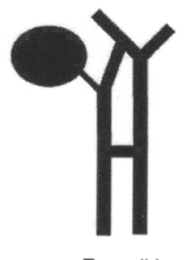

Type IV 


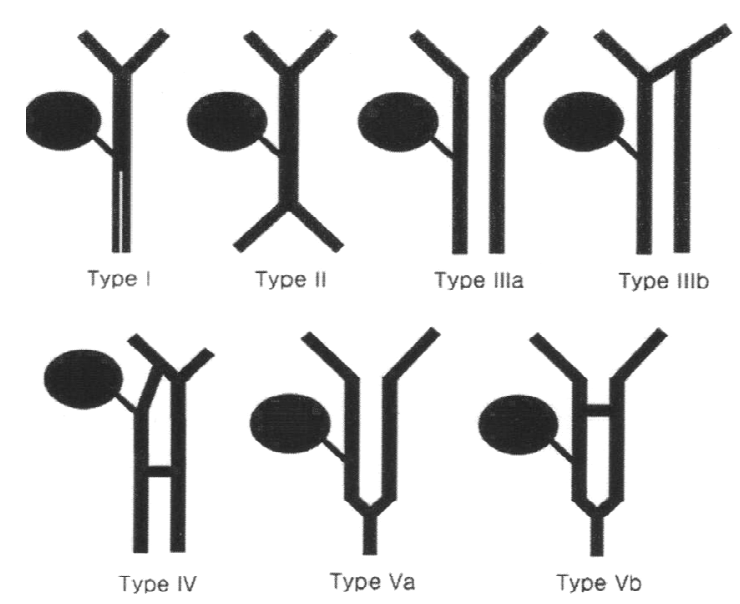

The morphological classification of double extrahepatic bile duct has been modified because the newly reported cases could not be included in existing classification system ${ }^{5}$. Choi et al when reporting as a type $\mathrm{Va}$ case, added type $\mathrm{Va} \& \mathrm{Vb}$ to classification system that was modified by Saito et al. the individual subtype of the modified classification system is as follows ${ }^{5-}$

- Type I: a CBD with septum in lumen.

- Type II: a CBD that bifurcates and drains separately.

- Type IIIa: double biliary drainage without extrahepatic communicating channels \& without intrahepatic communicating channels.

- Type IIIb: double biliary drainage without extrahepatic communicating channels with intrahepatic communicating channels.

- Type IV: double biliary drainage with one or more extrahepatic communicating channels

- Type Va: single biliary drainage without extrahepatic communicating channels

- Type Vb: single biliary drainage with extrahepatic communicating channels

CONCLUSION: Our case consists of a single long CBD, that is formed by distal convergence of two long extrahepatic bile ducts, thus qualifying for type Va variety5. Since the cystic duct most likely does not drain into the CBD, we can conclude that common hepatic duct is absent. Moreover,our case represents an incomplete duplication of extrahepatic biliary system, so we can logically infer that the disruptive event during organogenesis occurred relatively later than seen in case of true duplication.

CLINICAL ISSUES: Clinical issues for these anomalies are the combined complications and concomitant AUPBD 2 . In a review of Japanese clinical literature by Yamashita et al, the investigators found cholelithiasis in $28 \%$ of cases, a choledochal cyst in $11 \%$ cases,AUPBD in $30 \%$ cases and cancer in $26 \%$ cases $^{2}$. These investigators also emphasised that the opening site of the accessory bile duct was associated with a type of cancer and the concomitant presence of $\mathrm{AUPBD}^{2}$. Making a correct diagnosis of these anomalies prior to biliary surgery is clinically important due to risk of biliary injury during the operation ${ }^{2-8}$. 


\section{REFERENCES:}

1. Teilum D. Double common bile duct. Case report and review. Endoscopy. 1986;18:159161. [PubMed]

2. Yamashita K, Oka Y, Urakami A, Iwamoto S, Tsunoda T, Eto T. Double common bile duct: a case report and a review of the Japanese literature. Surgery. 2002;131:676-681. [PubMed]

3. Leung B, Lai P, Chan A, Chan YL, Lau WY. A variant of an accessory common bile duct. Endoscopy. 2000;32:728-730. [PubMed]

4. Balbinot RA, Gobbato A, Balbinot SS, Mendonca L, Tefilli N, Lain VV, et al. Double bile duct with ectopic drainage into stomach. Gastrointest Endosc. 2004;60:661-662. [PubMed]

5. Choi E, Byun JH, Park BJ, Lee MG. Duplication of the extrahepatic bile duct with anomalous union of the pancreaticobiliary ductal system revealed by MR cholangiopancreatography. Br J Radiol. 2007;80:E150-E154. [PubMed]

6. Lee JH, Yu JS, Park MS, Yoon DS, Yang SW. MR cholangiography of accessory bile duct connected to the stomach. AJR Am J Roentgenol. 2007;189:W344-W347. [PubMed]

7. Djuranovic SP, Ugljesic MB, Mijalkovic NS, Korneti VA, Kovacevic NV, Alempijevic TM, et al. Double common bile duct: a case report. World J Gastroenterol. 2007;13:3770-3772. [PubMed]

8. Bender EA, Springhetti S, Shemisa K, Wittenauer J. Left-sided gallbladder (sinistroposition) with duplication of the common bile duct. JSLS. 2007;11:148-150. [PMC free article] [PubMed]

9. Saito N, Nakano A, Arase M, Hiraoka T. A case of duplication of the common bile duct with anomaly of the intrahepatic bile duct. Nippon Geka Gakkai Zasshi. 1988;89:12961301. [PubMed]

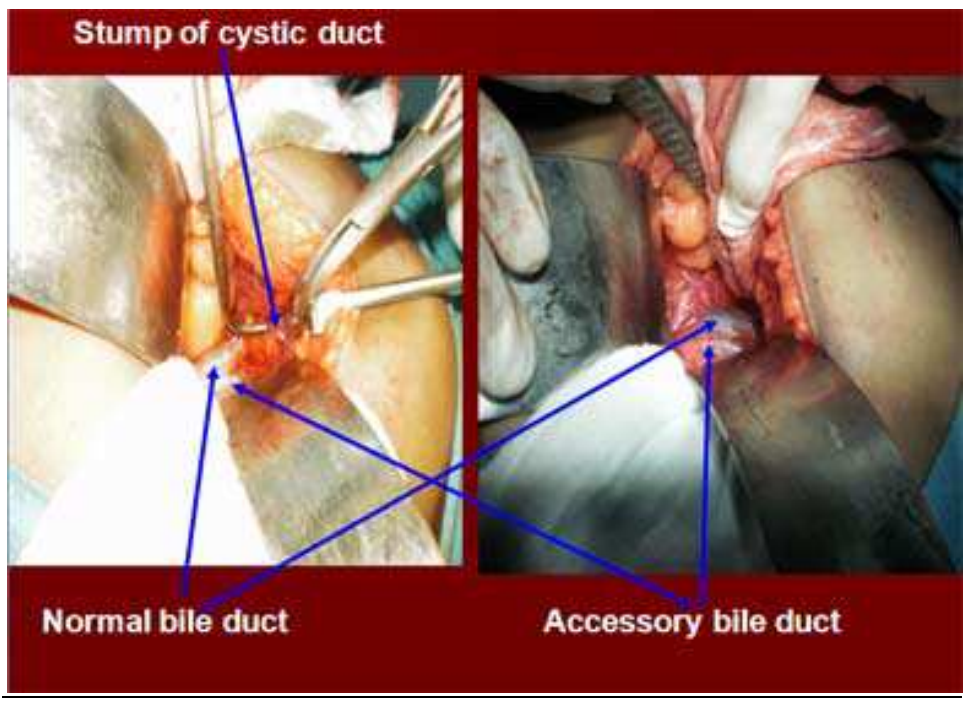




\section{CASE REPORT}
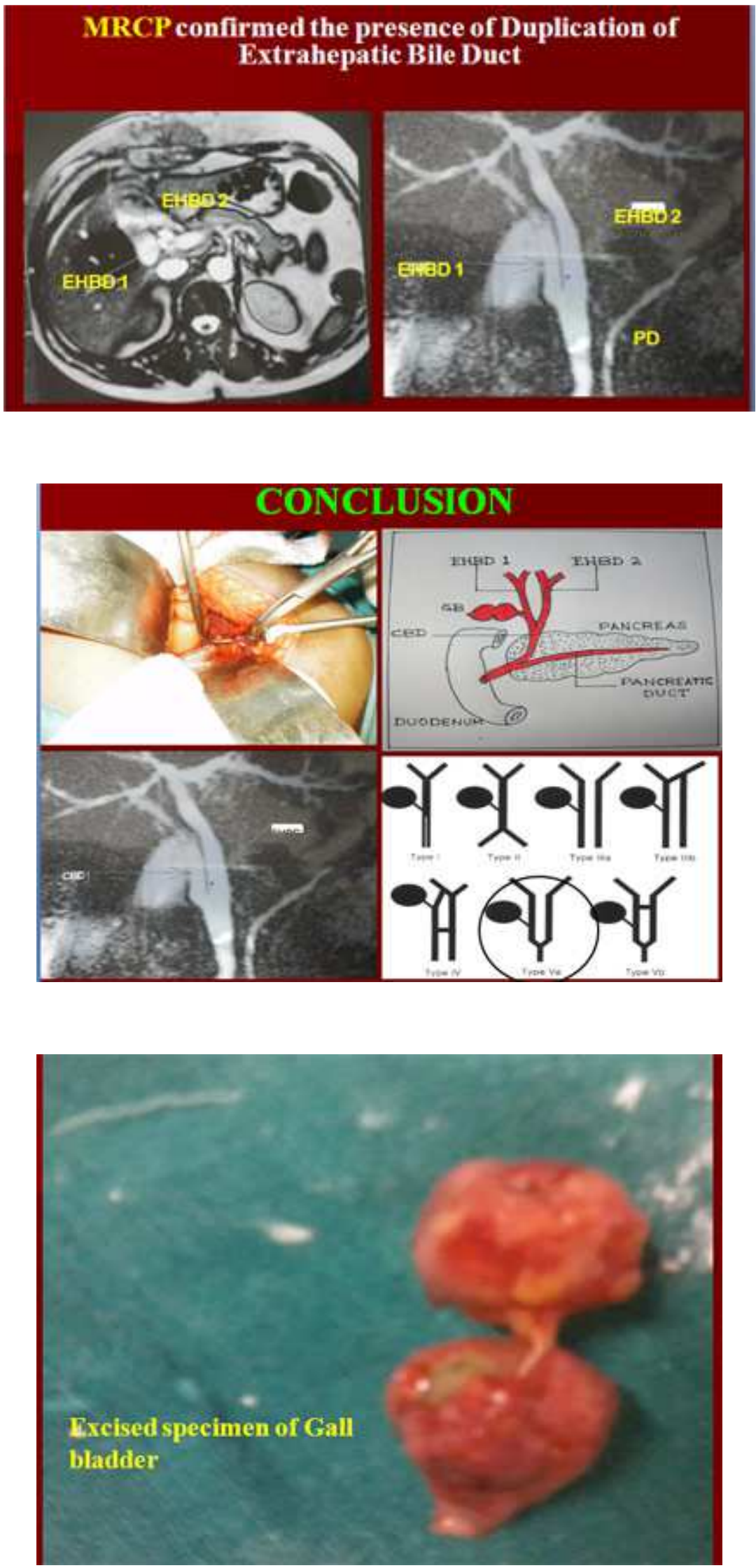